\title{
El canon literario de las gramáticas: los dictámenes de Jean Chapelain en la Nouvelle méthode espagnole de Lancelot (1660)
}

\section{The Literary Canon in Grammars: Chapelain's Judgements in Nouvelle méthode espagnole by Lancelot (1660)}

Carmen QujJada Van den Berghe

Departamento de Lengua Española ACEPTADO: 26 DE JUNIO DE 2016

Universidad de Salamanca

Plaza Anaya s/n. Salamanca, 37008

carmenq@usal.es

Orcid ID: 0000-0003-4575-1599

Resumen: Este trabajo se centra en las autoridades y ejemplificación literarias de la gramática española, a través del análisis de la Nouvelle méthode pour apprendre facilement et en peu de temps la langue espagnole (NME) de Claude Lancelot (1660). En particular, nos fijamos en cómo permean en ella los juicios literarios de la época, a través de la correspondencia mantenida con el hispanista Jean Chapelain. Tras un examen detenido de la NME, se concluye que la erudición del gramático de Port-Royal se ve avalada y reforzada por (i) los consejos procedentes de la crítica literaria, (ii) la consulta de crestomatías poéticas (Arte poética española, Rengifo 1592) y (iii) el aprovechamiento de otras gramáticas (La Parfaicte Methode, Charpentier 1596). Lancelot reserva, no obstante, un pequeño espacio para sus propios juicios estéticos: por un lado, de su selección destacan algunos autores religiosos como Rivadeneyra, fray Luis de Granada o Juan de Ávila y, por otro, alaba el éxito de Gracián.

Palabras clave: Historiografía gramatical. Ejemplificación literaria. Canon de autoridades. Crítica literaria.
Abstract: This paper examines the use of authors and literary exemplification in the Spanish grammar, through the case of Nouvelle méthode pour apprendre facilement et en peu de temps la langue espagnole (NME) by Claude Lancelot (1660). Specifically, we focus on the influence of literary criticism, which is often detectable in the history of Spanish grammar. We conserve traces of this influence: two letters sent by Jean Chapelain to the grammarian of Port Royal. After analyzing the NME, we can conclude that Lancelot is well advised, not only by the literary criticism but also by poetic sources (Arte poética española, Rengifo 1592) and grammatical sources (La Parfaicte Methode, Charpentier 1596). Apart from these influences, Lancelot makes room for his own esthetic ideas: he likes religious authors as Rivadeneyra, Fray Luis de Granada or Juan de Ávila, and he knows about Gracián's success.

Keywords: Grammatical Historiography. Exemplification. Literary Canon. Literary Criticism. 
ilustrandolo todo con exemplos a lo divino de buenos Poetas. Los quales no tanto pongo por la elegancia, (aunque esta no falta) quanto por la consonancia, que en ellos se enseña...

Juan Díaz Rengifo. Arte poética española, 1592

\section{INTRODUCCIÓN}

a génesis de este estudio se sitúa en un trabajo dedicado al uso de las autoridades literarias por parte de la gramática española del siglo XVII. Para ese periodo se puede constatar un fenómeno relativamente recurrente en la historia de nuestra codificación lingüística -en gramáticas (López Alonso; Quijada 2008 y 2011; Gómez Asencio 2016a y 2016b), pero también en diccionarios y ortografías-, como es la importancia del canon literario en obras de orientación lingüística, es decir, la influencia que los juicios estéticos procedentes de la preceptiva literaria ejercen en ámbitos estrictamente lingüísticos. Las recomendaciones de los críticos literarios a los gramáticos, cuando se trata de seleccionar muestras de lengua, se suceden de manera intermitente a lo largo de la historia de las letras españolas, con mayor o menor presencia dependiendo del tipo de destinatario y del enfoque de las obras, pero, sobre todo, dependiendo del dominio que el lingüista tenga de la lengua meta y su literatura. En la obra española de Claude Lancelot (ca. 1615-1695) -como también en la italiana- tenemos un caso evidente de este trasvase literario-lingüístico, y ello principalmente debido a que (i) Lancelot no conoce a la perfección el español, y (ii) tiene especial interés por la literatura española.

Tras una dedicación inicial a la preparación de gramáticas de lenguas clásicas (latín 1644; griego 1655), el abad de Port-Royal confecciona una primera gramática sobre la lengua vernácula de prestigio en la época (italiano, que publica en 1660, aunque debía de estar preparada algún tiempo antes). Y poco después, aprovechando una inmejorable coyuntura política para el estudio del español en Francia -el matrimonio entre Luis XIV y María Teresa de Austria-, saca a la luz la obra española que nos ocupa conformada según la horma de la italiana, aunque algo más sintética y simplificada. ${ }^{1}$ Finalmente, culmina su

1. Acerca de la NME de Lancelot pueden consultarse, entre otros (ver Esparza Torres), Morel Fatio 1901; Collet Sedola 1973-1974, 1991 y 1996; Hernández Sánchez/López Martínez 1988 y 1990; Martínez Gavilán, Maux-Piovano 2000 y 2008; Sáez Rivera; Fournier/Raby; Esteba Ramos 2014; Díaz Villalba/Quijada. 
proyecto gramatical con la elaboración de la Grammaire générale et raisonnée junto al lógico Antoine Arnaud. La NME ocupa un lugar destacado en la producción gramaticográfica española de la Francia del XVII: lo corroboran el número de reediciones -hasta cinco en vida del autor- y los comentarios en manuales posteriores -no solo en el foco francés, también en la primera gramática académica de 1771-.

Pues bien, con respecto al tratamiento del lenguaje literario, se detectan puntos coincidentes en sus dos textos vernáculos (NMI y NME): (i) se estructuran de manera tripartita con una última parte dedicada a la poesía ${ }^{2}$ (las otras dos son para las "partes del discurso" y la sintaxis), (ii) emplean ejemplos literarios (concentrados esencialmente en la parte de sintaxis) y (iii) añaden una lista de autoridades en los prólogos. Se apartan, eso sí, en la consulta de fuentes bibliográficas: mientras que para la NME acude a Rengifo y a las recomendaciones de hispanistas, las referencias literarias de la NMI parecen ser fruto único de su competencia, con el consiguiente esfuerzo que le conlleva, tal y como reconoce:

Pour ce qui est de la Poësie qui fait la troisiéme partie de cet Ouurage, je l'ay pesque toute tirée de RENGIFO qui en a écrit doctement en Espagnol dans le siecle passé, \& qui a fait son liure qu'il intitule De l'Arte Poëtica Española, à l'imitation de celuy que TEMPO qui viuoit du tems de Petrarque, fit pour la Poësie Italienne, de laquelle DoLCE a encore écrit depuis plus particulierement.

Je n'auois veu aucun de ces Auteurs lors que je me mis à trauailler sur la poësie Italienne, non plus que l'Apollon du sieur BENZE DUPUIS, qui n'a fait presque que les suiure; \& j'auouë que si je les auois veus deslors, j'en aurois pû tirer beaucoup de oulagement. (Lancelot, NME, prefacio $)^{3}$

\section{Tradición gramatical basada EN los CORPUS Literarios}

Antes de profundizar en el asunto que nos concierne, contextualizaremos histórica y metodológicamente este tipo de manuales, basados en el lenguaje literario y surgidos en un enclave histórico concreto. Algunas gramáticas del siglo

2. Más adelante, en 1663 , recolecta íntegramente las secciones sobre poesía italiana y española, a las que incorpora la latina y la francesa, y todo ello aparece en una sola obra titulada Quatre traités de poèsies latine, française, italienne et espagnole.

3. La negrita en las citas, de aquí en adelante, es nuestra. 
XVII muestran cierta preocupación por el tipo de español que quieren enseñar. Así pues, incluyen observaciones sobre el registro o la variedad lingüística elegida, y a ellas nos tenemos que remitir a la hora de configurar los diversos factores de su norma lingüística: (i) uso general (el común de los hablantes); (ii) uso de los cultos y eruditos (el propio de los gramáticos y doctos); (iii) uso de los autores literarios; (iv) atención a diferentes variedades diastráticas (uso de la corte frente al del pueblo); (v) variedades diacrónicas (lenguaje propio de las composiciones españolas de los siglos XV y XVI frente a las innovaciones de los "jóvenes autores" del XVII); y (vi) variedades diatópicas (norma castellana frente a la andaluza, por ejemplo). En la NME de Lancelot estos factores están presentes en mayor o menor medida (Medina Morales), pero sobresalen (i) el uso del propio gramático, (ii) el de otras autoridades lingüísticas citadas expresamente -como Nebrija, Miranda, Rengifo, Covarrubias o Quintiliano-, y (iii) el uso de literatos, de elevada consideración para el autor francés.

Desde el punto de vista metodológico, la obra española de Lancelot se podría situar en un estadio muy incipiente de la tradición gramatical basada en los corpus literarios. En dicha corriente, la presencia de ejemplos literarios estaría vinculada al afán "descriptivista" del gramático (Lliteras). Es decir, no solo se trata codificar la lengua española a través de un número de reglas o normas más o menos cerrado, sino también de describir los usos excepcionales y las figuras de dicción que provee principalmente la literatura. La consideración de que a mayor número de figuras de dicción (esto es, de "irregularidades" léxicas o sintácticas), más elegante es una lengua la vemos, sin ir más lejos, en una de las recomendaciones que ofrece a Lancelot el hispanista y crítico literario de la época, Jean Chapelain: ${ }^{4}$

N'auriés-vous point peu traitter plus amplement des irréguliers soit dans les mots, soit dans la syntaxe, et vos autheurs ne vous secouroientils point en cela? Plus une langue en a, plus elle est élégante, les dérogations à la regle, quand elles sont establies, faisant leurs principales figures de diction. (carta del 10 de octubre de 1659; Tamizey de Larroque 56) La descripción del lenguaje literario -consustancial en la tradición gramatical clásica-, se afianza durante el siglo XVII, ${ }^{5}$ solo cuando la producción literaria

4. Para la correspondencia de Chapelain, se ha utilizado la edición preparada por Tamizey de Larroque en 1883 . Ver nota 9.

5. Al menos en el ámbito estrictamente gramatical; desde una perspectiva más integradora, ver las disquisiciones sobre el lenguaje literario del Diálogo de la lengua de Valdés en el siglo XVI. 
española está ya consolidada y ha alcanzado el más alto reconocimiento a nivel nacional y europeo. No obstante, en esta época el empleo de autoridades y ejemplos literarios aún no es sistemático en las gramáticas, ni mucho menos. ${ }^{6}$ No será hasta los siglos XVIII y XIX -con el Arte del Romance Castellano de Benito de San Pedro 1769 y, aún más acusado, a partir de la Gramática de la lengua castellana según ahora se habla de Vicente Salvá 1830-, cuando encontremos una descripción detallada de los usos literarios, toda vez que la sintaxis se esté perfeccionando en tanto que disciplina gramatical.

Para la época en que nos situamos, esto es, el siglo XVII, muchos textos de enseñanza del español publicados fuera de nuestras fronteras incluyen apéndices con crestomatías literarias a modo de iniciación a la lectura de los clásicos españoles y/o recomendaciones literarias en los prólogos. Claro está que aquí las muestras literarias no tienen la misma función que la de la corriente basada en corpus literarios, por lo que habremos de realizar una diferenciación metodológica esencial.

\section{VALOR DE LAS REFERENCIAS LITERARIAS: GRAMATICAL Y EXTRAGRAMATICAL}

El ejemplo o autoridad literaria tiene, en todo momento, una intención que va más allá de lo estrictamente gramatical: es el instrumento que muestra la erudición del autor, introduce al lector en la literatura o trata de ennoblecer la lengua en cuestión. En esta época, solo en determinados manuales viene dotado, además, de la concepción metodológica de ilustrar una regla gramatical o incluso de favorecer inductivamente la comprensión de un determinado comportamiento morfosintáctico, léxico u ortográfico. Así pues, distinguimos una doble funcionalidad de estas muestras de lengua:

a) Funciones extragramaticales, es decir, aquellas con un valor puramente literario y cultural:

- Dignificación de la lengua. La enumeración de autoridades sobresalientes de una lengua vernácula es un procedimiento típico en las obras lingüísticas de los Siglos de Oro, con el propósito de ennoblecerla y elevarla al estatus de una lengua clásica.

- Breve guía y recomendación de lectura. Estos ejemplos se convierten en una pequeña introducción a la literatura de una lengua, y

6. Destacamos, sin embargo, la minuciosidad de Correas en su capítulo sobre figuras y poética españolas incluido en el Arte grande de la lengua castellana 1626. 
mediante tales extractos el lector puede estar al corriente de las principales obras y tendencias literarias. De especial interés resultan las listas de autores y obras destinadas a un público extranjero, pues constituyen una valiosa fuente de información sobre la difusión de la literatura española en Europa. Normalmente, bajo esta aproximación a las composiciones españolas se esconden también intereses comerciales de los autores y editores de gramáticas, como reclamo decisivo a la hora de vender sus obras.

- En última instancia, los ejemplos evidencian la erudición del gramático. Las autoridades dejan ver la riqueza y el dominio filológico del autor.

b) Funciones gramaticales, es decir, aquellas insertas en el tejido discursivo -argumental o expositivo- de la gramática:

- Ilustración de las reglas gramaticales.

- Muestras de lengua para la deducción de las reglas gramaticales.

- Descripción de usos excepcionales (o "irregulares") aceptados por el gramático.

- Crítica de determinados usos (suponen contraejemplos de una regla).

Como ya se ha dicho, en las gramáticas de los Siglos de Oro son relativamente frecuentes los ejemplos y autoridades con una motivación no gramatical. Así pues, muchos de los manualistas extranjeros (o cuyos principales destinatarios son extranjeros) incluyen nóminas de autores en los prólogos, en las dedicatorias al lector o en los apéndices finales. Es el procedimiento de, por ejemplo, Ambrosio de Salazar, Antoine Fabre, John Minsheu o Marcos Fernández. Menos habitual es que a tales ejemplos se les proporcione además una funcionalidad gramatical. En Quijada 2008 destacamos el uso lingüístico sistemático del corpus literario por parte de tres gramáticos extranjeros (Charpentier, Sanford y Lancelot) y uno español (Correas) durante el periodo entre finales del siglo XVI y el siglo XVII.

Claude Lancelot es consciente del enorme aprovechamiento que se puede extraer de los textos literarios. Para comenzar, ofrece al lector en el prefacio una guía con los mejores autores españoles -que no cultivan necesariamente la lengua española, sino la latina, como Lucano, Marcial, Séneca-. Primero cita a algunos gramáticos, lexicógrafos y pedagogos, y después a poetas y prosistas, con las correspondientes recomendaciones sobre sus virtudes y obras. Ya en el cuerpo de la gramática inserta algunos ejemplos literarios en la parte de sintaxis y finaliza con un análisis exhaustivo de la literatura española en la última parte. 
Las recomendaciones de Jean Chapelain con respecto al provecho que de la literatura se puede extraer en una gramática tienen una decisiva influencia en Lancelot. El hispanista destaca, por encima de todos los consejos, las ventajas de preparar un texto introductorio sólido y rico en información:

Sourtout je vous exhorte à faire une ample préface qui embrasse tous les motifs que vous avés eu en le composant pour le rendre accompli. Je suis tousjours pour les préfaces discourues et solides. Le lecteur en est conduit comme par la main à l'intelligence du livre, et l'autheur y a moyen de faire voir sa richesse et sa conduitte à l'employer. (Carta del 10 de octubre de 1659; Tamizey de Larroque 57)

Y, efectivamente, a través de un exhaustivo prefacio de trece páginas, Lancelot incita al lector a estudiar español (arguye razones comerciales, políticas y culturales), le proporciona datos sobre su origen, historia y autoridades ilustres, anticipa la estructura del método (para esa cuestión remite a la de su gramática italiana), ofrece recomendaciones sobre los principales autores españoles y sus obras, y, por último, señala que determinada información va destinada al lector ya iniciado (arabismos, conjugación de los verbos auxiliares y de los irregulares, y particularidades sintácticas).

Con respecto a la pertinencia de incluir un capítulo sobre poesía española en su gramática, los consejos de Chapelain son rotundos: "En fin vous devés toucher cette matière [la poesía] autant à fond que vous le pourrés. Ce sera un gran ornement à vostre ouvrage et il le rendra plus instructif et plus curieux qu'aucun de ceux qui ont esté faits de ce genre-là" (Carta del 10 de octubre de 1659; Tamizey de Larroque 57).

\section{Procedimientos en la Selección de ejemplos literarios}

Es difícil trazar con precisión el proceso de selección de autores y ejemplos literarios. Muchas veces, el gramático combina la información directa -de su propia lectura de la literatura- con la de otros manuales o con recomendaciones de especialistas. Cabe hacer aquí una distinción entre los gramáticos españoles, por lo general conocedores en profundidad de la literatura de su país, y los extranjeros, algunos no demasiado eruditos, que tienen que acudir a crestomatías o que toman prestados los ejemplos de otras gramáticas. Hay que tener en cuenta, además, que no todos los manualistas extranjeros acceden con la misma facilidad a las ediciones de reciente publicación. 
Con el fin de sistematizar el estudio del canon de autoridades literarias en las gramáticas, proponemos cuatro mecanismos principales a través de los cuales los gramáticos escogen sus ejemplos literarios (procedimientos que suelen combinarse en la mayoría de los casos):

(i) Fuentes directas

Algunos gramáticos parecen manejar directamente las obras literarias, tal y como podemos deducir de la completa información que ofrecen Charpentier, Minsheu o Sanford: especifican la edición manejada (lugar y año) y a veces incluso la página exacta.

(ii) Crestomatías literarias, tratados de retórica y poética

Este tipo de obras es muy popular entre los gramáticos, ya que, además de proporcionar un amplio repertorio de ejemplos, estos aparecen agrupados por figuras de dicción, tropos o tipos de composiciones. Hay constancia de que se utilizan, por ejemplo, las obras de Juan Díaz Rengifo (Arte poética española 1592), Melchor de Santa Cruz (Floresta española de apotegmas y dichos graciosos 1574), Juan Huarte de San Juan (Examen de ingenios 1575) o Pierre Bense-Dupuis (L'Apollon, ou l'oracle de la poésie italienne et espagnole 1644). Tales recopilaciones gozan de un gran éxito editorial en Europa.

(iii) Recomendaciones de críticos literarios e hispanistas extranjeros

Algunos de los gramáticos extranjeros no tienen un conocimiento práctico del español y se rodean de los principales eruditos y críticos literarios de su país, para que supervisen y corrijan sus obras.

(iv) Selección de otras gramáticas

La huella de los métodos precedentes se rastrea en mayor o menor medida en la mayoría de textos áureos. Uno de los casos más evidentes es el calco de los ejemplos literarios de César Oudin por buena parte de sus continuadores: Franciosini, Doergank, Fabre o Sobrino.

La selección de ejemplos es, en última instancia, una decisión personal del gramático. En el caso de Lancelot, varios estudiosos han señalado deficiencias en su conocimiento práctico del español. ${ }^{7}$ Tal como él mismo reconoce en el prólogo, se sirve de la obra de Rengifo para confeccionar la parte sobre poe-

7. Maux-Piovano (2000, 55) o Esteba Ramos (2005, 64). Antes, Collet Sedola había apuntado la manera de compensar esta falta de contacto directo con el español a través de "son intelligence des langues, et par la large compréhension de leur estructures et de leur mécanismes" (19731974, 257). 
sía española y parece haber consultado el Apollon de Bense-Dupuis para la poesía italiana, a pesar de no haberlo utilizado para la NMI (ver la cita que cierra la introducción). Junto al aprovechamiento de estas lecturas, a continuación agradece expresamente a una figura de la Academia Francesa ("un des plus hábiles hommes de l'Academie Françoise") la atenta revisión que ha realizado de sus manuales español e italiano. Personaje anónimo "cuya modestia", en palabras de Lancelot, "le impide revelar su mérito", y que con toda probabilidad se trata de Jean Chapelain (1595-1674).

En opinión de Lancelot, junto al material "inerte" ("regles mortes de la Langue") que proporcionan los tratados de gramática, lexicografía o poética -algo desfasados en el tiempo, al menos los que él cita-, es necesario tener en cuenta las valoraciones y críticas de los entendidos de la época, posiblemente más actualizadas y fiables:

Mais j'estimerois avoir fait peu de chose de consulter ces regles mortes de la Langue, si en mesme temps je n'en avois fait juge l'un des plus habiles hommes de l'Academie Françoise dont la modestie m'empesche de relever le merite, et à qui le Public sera redevable de la bonté qu'il a euë de revoir cette Grammaire Espagnole avec encore plus de soin qu'il n'avoit fait l'Italienne. (Lancelot, NME, prefacio)

De esta manera, en la NME de Lancelot se distinguen, al menos explícitamente, dos vías de penetración de autoridades literarias: Rengifo y Chapelain. Comprobaremos más adelante, cuando analicemos en profundidad su canon literario (ver epígrafe 5), que ciertos ejemplos no se rastrean en ninguno de los dos, pero sí en otro gramático, y que otros incluso parece haberlos seleccionado él mismo.

\section{InfluenCia de Chapelain EN EL PREFACiO DE LA NME}

Chapelain revisa la Nouvelle méthode espagnole, sus huellas son fáciles de detectar. La crítica del siglo XIX lo señala y así, autores como Sainte Beuve o MorelFatio ponen de relieve esta filiación: "Ce fut probablement par M. d'Andilly [consejero real, miembro de Port-Royal] que Lancelot fut mis en rapport avec Chapelain [...] c'est sourtout pour la Méthode Espagnole que Chapelain lui fut d'un grand secours" (Sainte Beuve 560-61). Morel-Fatio, en sus Études sur l'Espagne de 1888, también señala que Chapelain había participado en la redacción de la NME. 
Calificado como "árbitro literario de su tiempo" y el "oráculo de los poetas de su tiempo", Chapelain "se convirtió en el consejero de casi todos los escritores de su época [...] asesoró a unos, estimuló a otros, corrigió, revisó y criticó a todos" (Colomer 604). Desde su posición de teórico de la literatura, y como hombre fuerte de la Academia Francesa y de la política de Luis XIV, mantiene buenas relaciones con los señores de Port Royal y, a pesar de no ser jansenista, admira a Arnauld y a Andilly (Collas 67-74). Recomendado posiblemente a través de este último, Lancelot entra en contacto con el crítico para que revise y avale su texto, toda vez que este conoce bien la literatura española e incluso en sus comienzos profesionales se había dedicado a la enseñanza del español. ${ }^{8}$ Chapelain responde a su petición -tenemos constancia del envío de al menos dos cartas, fechadas el 10 de octubre y el 21 de diciembre de $1659^{\circ}-\mathrm{y}$ cumple con la encomienda: (i) en primera instancia alaba el trabajo del gramático, ${ }^{10}$ (ii) a continuación corrige erratas directamente en una copia de la NME, y, por último (iii), le aconseja sobre cuestiones de gramática y, sobre todo, de literatura. En ocasiones se muestra cauto o modesto, y recuerda a Lancelot que su vínculo con la lengua española ya no es tan fuerte como antes y que es posible que no esté al día de innovaciones lingüísticas o autores literarios nuevos:

Vous jutiffierez par vos autheurs si j'en ay eu raison de douter et vous vous y réglerez par eux plustost que par moy qui, depuis trente annés, n'ay point eu d'application à cette langue, de sorte que je puis facilement m'estre abusé [...] Voicy les lumières que je vous en puis donner de ce qui m'en reste en la mémoire. (carta del 10 de octubre de 1659; Tamizey de Larroque 56)

8. Colomer refiere que "entró primero al servicio del barón du Bec como profesor de español y más tarde se encargó de la educación de los hijos del marqués de la Trousse" (604), para quienes tradujo al francés el Guzmán de Alfarache (Le gueux, ou la vie de Guzmán d'Alfarache, Image de la vie bumaine 1619-1620), obra que le reportó considerable éxito editorial y reconocimiento, a pesar de que renegara de ella más adelante.

9. Parte de la correspondencia de Chapelain fue editada cuidadosamente entre 1880 y 1883 por el historiador y editor Tamizey de Larroque, quien en la advertencia del tomo I alude a los entresijos y las dificultades de conservación de la colección completa de cartas. El primer tomo comprende el periodo de 1632 a 1640 (en Jouhaud pueden consultarse los principales destinatarios y la temática de la correspondencia) y el segundo, el que nos interesa, abarca los años 1659 a 1672.

10. "La méthode m'en a paru excellente à vostre ordinaire et je me fais violence de ne vous la pas plus louer" (carta del 10 de octubre de 1659; Tamizey de Larroque 56), "vous avés une si grande habitude à bien faire que les choses les plus difficiles vous sont aisées et que vous ne faittes pas tout seulement bien, mais encore prontement" (carta del 21 de diciembre de 1659; Tamizey de Larroque 72). 
Il y eu peut avoir tout plein d'autres [auteurs] desquels je ne me souviens pas ou qui ne sont pas venus à ma conoissance. (carta del $21 \mathrm{de}$ diciembre de 1659; Tamizey de Larroque 74)

A pesar de que la crítica literaria posterior se haya servido de esta correspondencia para estudiar la difusión y valoración de la literatura española en la Francia del siglo XVII, ${ }^{11}$ no parece que la historiografía gramatical más reciente le haya concedido mayor importancia, si exceptuamos la breve mención de Collet Sedola (1973-1974, 253-54) recogida por Sáez Rivera (333-34). Pensamos que esta influencia ha de ser interpretada bajo la perspectiva de la historia de nuestras gramáticas, puesto que la figura de Chapelain es decisiva como revisora de un texto gramatical y porque a través de ella somos testigos excepcionales del procedimiento en la selección de ejemplos y modelos de lengua; de cómo se prepara una gramática, en definitiva.

A continuación, desglosamos las huellas detectadas en el prólogo de la NME:

\section{Alusiones indirectas a fean Chapelain}

En ningún momento nombra directamente al hispanista, pero en varias ocasiones podría estar aludiendo a él, a la hora de señalar sus fuentes y colaboradores:

C'est de ces naturels Espagnols que j'ay tiré particulierement le petit Ouvrage que je donne icy au public, en y meslant aussi ce que j'ay pû tirer des Estrangers qui ont travaillé sur le mesme sujet avec plus de soin; et des personnes habiles que j'ay pû consulter sur cette Langue. (Lancelot, NME, prefacio)

Mucho más evidente es el agradecimiento expreso a un personaje de la Academia Francesa (ver cita del epígrafe 3).

11. Destacamos, entre otros, los trabajos de Lanson, Péligry 1974, 1975, 1988a y 1988b, Cioranescu 1977 y 1983, Colomer, y Losada. Desde el ámbito de la historia del libro, merece especial atención la opinión de Péligry: "Este manual [NME] apareció el año siguiente con el seudónimo de Trigny; fruto de la colaboración estrecha entre los dos eruditos, el librito se componía de tres partes: una morfología, una sintaxis y una especie de introducción a la literatura española en que la influencia de Chapelain fue sin duda determinante. Sus cartas indicaban en efecto a Lancelot los poetas y los prosistas que escribían mejor en castellano y merecían el honor de figurar en una antología" (Péligry 1988a, 308). 


\section{Dedicatoria a la reina María Teresa}

La crítica coincide en constatar una clara influencia de Chapelain cuando Lancelot dedica su obra "A la serenissime Infante d'Espagne, Doña María Teresa, que toute la France considere déja comme sa Reine". Sainte-Beuve comprueba el efecto que surte en Lancelot la última frase de las cartas de su colaborador, quien le instiga a publicar enseguida su manual aprovechando la coyuntura política:

Je finis en vous exhortant à publier au plustost ces deux grammaires, surtout cette dernière pour préparer nos François à se faire entendre lorsqu'ils iront à l'adoration de la nouvelle Reyne et qu'ils luy voudront tesmoigner qu'ils ne sont pas moins bons Espagnols que bons François. (carta del 21 de diciembre de 1659; Tamizey de Larroque 75)

Lancelot recoge audazmente esta idea y la desarrolla en su dedicatoria, en la que alaba a la nueva reina y señala el propicio momento de paz entre los dos reinos.

\section{Canon literario en el prefacio}

Como se comprobará en el apartado 5, el canon propuesto en las páginas introductorias de la NME muestra claras concomitancias con el recomendado por Chapelain. Consciente este de que podría haberle brindado información más detallada, se excusa ante la falta de tiempo que le ha impedido seleccionar ejemplos concretos. ${ }^{12}$

No obstante, la nómina no es escueta. Conocemos con relativo detalle, gracias a los estudios de historia literaria e historia del libro, el contenido de la biblioteca del erudito, una de las más sobresalientes de su época en el país vecino (ver Briquet). Según los datos de Péligry (1988a, 312), de las aproximadamente trescientas obras hispánicas que se han contabilizado, casi la mitad son literarias (el $46 \%$ ), seguidas de las históricas (30\%) y las científicas (17\%). De manera minoritaria aparecen obras de carácter religioso $(6,3 \%)$ y jurídico $(1,4 \%)$.

12. "De vous en fournir d'autres [exemples] il me faudroit faire une trop long estude et mes affaires ne me le permettent pas, ces heures mesmes que j'y ay employées estant prises sur le temps destiné à l'ouvrage que vous sçavés et qui fait mon occupation nécessaire" (carta del 21 de diciembre de 1659; Tamizey de Larroque 72). 


\section{Fuicios literarios}

El gramático de Port-Royal respeta y valora las críticas literarias de Chapelain, ya que, además de recoger su nómina de mejores autores e insertarla en el prefacio, también se hace eco de sus juicios literarios, muchas veces incluso literalmente:

Lazarillo de Tormes pour la première partie est un chef-d'oeuvre de langue $[\ldots]$

Il y a une histoire de Juan II de Portugal d'un stile fort élegant et de l'air des bons anciens. (Chapelain, carta del 21 de diciembre de 1659; Tamizey de Larroque 74)
La premiere partie de Lazarillo passe pour vn chef-d'œuvre de la Langue $[\ldots]$

L'histoire de Jean II. de Portugal écrite depuis vingt ans par un Portugais, est fort Castillane et d'un air qui tient des bons Auteurs.

(Lancelot, prefacio de la NME)

Arabismos e irregularidades léxicas y sintácticas

Chapelain, tras elogiar la gramática, anota dos aspectos que echa en falta: (i) un capítulo específico sobre préstamos árabes ${ }^{13}$ y (ii) un tratamiento más profundo de las irregularidades léxicas y semánticas. Lancelot toma nota de ambas sugerencias y las menciona rápidamente al final del prefacio, como breves apuntes para los que quieran avanzar más en el estudio del español. En lo que concierne a arabismos e irregularidades léxicas, el gramático remite a la atenta lectura de los autores. El apartado de irregularidades sintácticas se presenta más reforzado a través de la segunda parte sobre "Quelques Remarques curieuses sur la Syntaxe et la proprieté du discours".

\section{Correcciones}

Junto a las sugerencias, Chapelain también ejerce de revisor y anota las correcciones en una hoja aparte, que no se ha conservado. Ciertas "faltas" -así denominadas- se cuelan en la NME. Entre ellas, destacan: (i) errores tipográficos (“de copista”), (ii) dudas sobre la utilización de ciertas palabras (¿españolas o extranjeras?) y (iii) el empleo de algunos términos en desuso:

Entre ce qu'on y peut nommer fautes, j'y en ay rencontré plusieurs de copiste que j'ay marquées en partie sur mon papier, et qu'en par-

13. "J'aurois voulu que vous y eussiés fair un chapitre particulier du mélange de l'arabe avec ce langage. C'auroit esté pour vous une occasion de monstrer de l'érudition" (carta del 10 de octubre de 1659; Tamizey de Larroque 56). 
tie j'ay corriges sur le vostre. Il y faudra regarder de fort près lorsqu'on imprimera, car la Grammaire est le fondement de tout le reste, et la moindre erreur d'ortographe mesme influe en tout ce qui est basti dessus. J'ay douté de quelques mots s'ils estoient Castillans ou non [...] Il m'a semblé que vous y aviés employé quelques termes si vieux qu'ils n'ont plus d'usage, et mon opinion seroit qu'il ne les faudroit point mettre ou qu'il les faudroit noter. (carta del 10 de octubre de 1659; Tamizey de Larroque 56). J'ay leu ce travail avec attention, comme les précedents, pour ne vous manquer non plus en cette rencontre qu'aux autres puisque vous desiriés cette assistance de moy. Tout m'en a semblé accomply à quelques petits scrupules près que vous trouverés dans le papier que accompagnera cette lettre. (carta del 21 de diciembre de 1659; Tamizey de Larroque 72)

\section{Autoridades Literarias EN LA NME}

\section{Configuración del canon literario del prefacio}

Lancelot ofrece varias listas de figuras canónicas en el prólogo: (i) autores españoles que cultivan la lengua latina, (ii) gramáticos y lexicógrafos españoles y (iii) literatos y obras españoles. Con respecto a este último grupo, el que aquí interesa, mostramos a continuación su contraste con el que se desprende de las cartas de Chapelain:

\begin{tabular}{|c|c|c|c|}
\hline \multicolumn{4}{|c|}{ AUTORES MENCIONADOS CON VALORACIÓN POSITIVA TANTO EN LAS CARTAS DE CHAPELAIN COMO EN EL PREFACIO DE LANCELOT } \\
\hline Fray Luis de Granada & Ribadeneyra & Santa Teresa de Jesús & Mariana \\
\hline Montemayor & Lope de Vega & Boscán & Garcilaso de la Vega \\
\hline Villamediana & Castillejo & Ercilla & Juan Rufo \\
\hline Juan de Mena & Manrique & Romances anónimos & Historia de Juan II de Portugal \\
\hline Lazarillo de Tormes & & & \\
\hline AUTORES MENCIONADOS EXCLUSIVA & IENTE POR CHAPELAIN & AUTORES MENCIONADO & EXCLUSIVAMENTE POR LANCELOT \\
\hline $\begin{array}{c}\text { CON VALORACIÓN } \\
\text { POSITIVA }\end{array}$ & $\begin{array}{c}\text { CON VALORACIÓN } \\
\text { NEGATIVA }\end{array}$ & $\begin{array}{c}\text { CON VALORACIÓN } \\
\text { POSITIVA }\end{array}$ & $\begin{array}{c}\text { CON VALORACIÓN } \\
\text { NEGATIVA }\end{array}$ \\
\hline $\begin{array}{l}\text { Jáuregui } \\
\text { Gaspar Lucas Hidalgo } \\
\text { Francisco López de Úbeda } \\
\text { Gil Polo } \\
\text { Góngora }\end{array}$ & $\begin{array}{l}\text { Mateo Alemán } \\
\text { Quevedo }\end{array}$ & $\begin{array}{l}\text { Juan de Ávila } \\
\text { Gracián } \\
\text { Ginés Pérez de Hita }\end{array}$ & Gracián \\
\hline
\end{tabular}

Tabla 1. Canon de autoridades literarias de Chapelain y del prólogo de la NME (Lancelot) 
La tabla evidencia una gran similitud entre los dos cánones. Ahora bien, hay tres autores que solo aparecen en la NME: Juan de Ávila, Baltasar Gracián y Ginés Pérez de Hita; los tres, además, son hasta tal punto exclusivos de Lancelot que no aparecen en ninguna otra gramática del siglo XVII (Quijada 2008). La aparición del místico Ávila tal vez esté relacionada con la religiosidad del gramático: "Les lettres d'AvilA, \& ses traittéz spirituels, meritent d'estre leus de toutes les personnes pieuses". Aunque Chapelain alude a Teresa de Jesús, fray Luis de Granada y Ribadeneira, no parecen interesarle especialmente los textos religiosos (Péligry 1988a, 314). También parece pasar por alto la novela histórica de Ginés Pérez de Hita, cuya primera parte -titulada Historia de los bandos de los zegries y abencerrajes, caballeros moros de Granada, de las civiles guerras que bubo en ella..., más conocida como Guerras civiles de Granada- aparece en 1595 en Zaragoza y de la que pronto se preparan ediciones en Francia e incluso traducciones y ediciones anotadas. ${ }^{14}$ Puede ser que no descifre la alusión de Lancelot ${ }^{15}$ o que simplemente la ignore.

Por último, Chapelain, que se jacta de que han pasado por sus manos la mayor parte de los libros españoles, desconoce el Héroe de Baltasar Gracián ("Cet Heroe de Graciano m'estoit tout à fait inconnu"). La obra, aparecida en 1637 en España, se traduce al francés en 1645 y constituye una muestra evidente de la erudición del gramático de Port Royal. No debe sorprender que el crítico ignore su existencia, ya que prácticamente la mayor parte de las obras hispánicas que posee en su biblioteca -un 80 \% de 300 en total, según Péligry 1988a, 314- salen de la imprenta antes de 1632, periodo a partir del cual las relaciones políticas entre Francia y España se tornan adversas, y ello coincide con la progresiva involucración de Chapelain en la administración regia de los asuntos culturales del país. Desde la historia de la literatura se ha señalado el desapego estético, cultural y, por supuesto, político, de Chapelain hacia las cuestiones españolas especialmente a partir del reinado de Luis XIV (lejos quedan su formación en la lengua española, sus lecturas juveniles y la traducción del Guzmán de Alfarache). La tardía fecha de la aparición del Héroe de Gracián

14. Cioranescu destaca el valor didáctico de la primera traducción de la obra en Francia: "L'œuvre de Pérez de Hita eut en France deux éditions en espagnol, publiées en 1606 et en 1660. Celle de 1606 avait été préparée par Fontan, un professeur d'espagnol, qui en donne aussi la première traduction (1608): celle-ci est un ouvrage pour ainsi dire utilitaire, destiné aux apprentis de la langue" $(1983,423)$.

15. "L'histoire du Royaume de Grenade ne cede à pas vn de ceux-cy estant encore auantageuse pour ceux qui commencent, en ce que dans quelques editions les mots difficiles sont expliquez à la marge en nostre langue" (Lancelot, prefacio de la NME). 
justificaría su desconocimiento, pero es que además el erudito francés condena a continuación el estilo afectado y artificial de los autores "modernos" españoles e italianos, en sintonía con el credo estético clasicista predominante en la Francia del siglo XVII. Chapelain rechaza el "style coupé", retorcido, corrompido, en el que "tout leur fait n'est qu'agudezas et en cela ils font consister tout le mérite d'un écrivain" (Colomer 608-09). Lancelot comparte esta opinión y la traslada prácticamente de manera literal:

Généralement les modernes Espagnols ont corrompu leur stile et sont tombés dans les figures bizarres et forcées dont vous accusés celuy-cy, justement comme les Italiens modernes ont fait sur le modelle du Malvezzi.

(Chapelain, carta del 21 de diciembre de 1659; Tamizey de Larroque 75) cet Auteur [Gracián] soit un peu enflé dans ses metaphores et forcé dans ses figures, aussi bien que Malvezzi parmy les Italiens. C'est une maniere d'écrire où plusieurs Auteurs modernes de ces deux Langues sont tombez, par une affectation qui les fera toûjours moins estimer que les anciens. (Lancelot, prefacio de la NME)

Así pues, ambos autores comparten su preferencia por literatos del XVI como Boscán, Garcilaso, Ercilla o Castillejo, con un estilo natural y depurado, procedente de Italia. Lancelot calca la última valoración:

Le temps où vivoit Boscan et Garcilasso, son amy, est depuis 1500 jusqu'à 1543. J'en ay les preuves assurées qui seroient longues à déduire. Ce sont les pères de la belle poësie espagnole qui ont presque seuls meslé l'érudition au beau naturel.

(Chapelain, carta del 21 de diciembre de 1659; Tamizey de Larroque 73)
Pour les Poëtes, BOSCAN et GARCILlasso, qui ont paru presque dés le commencement du quinziéme siecle, sont regardez comme les premiers et comme ceux qui ont commencé à méler l'érudition avec la beauté du naturel.

(Lancelot, prefacio de la NME)

Es cierto que el gramático se muestra algo menos severo en sus juicios; para él Boscán y Garcilaso serían los pioneros en combinar erudición y naturalidad -se entiende que vendrán otros detrás-, para Chapelain son casi los únicos en lograrlo. ${ }^{16}$ Además, no olvidemos que el gramático se hace eco del éxito de

16. Los especialistas en historia literaria se han pronunciado en varias ocasiones sobre el gusto (o la ausencia de él) y la supuesta hispanofobia de Chapelain. Sirvan como ejemplo las palabras de 
Gracián: "L'Eros [sic] de GRACIEN, et ses autres petits ouurages sont aussi fort estimez en ce temps". Chapelain alaba el buen gusto de la selección de Lancelot e interpreta la mención de autores menos estimados como la ocasión de mostrar su conocimiento:

Je vous sçay bon gré au reste d'avoir passé l'esponge sur toutes ces autres formes ridicules, puériles et gothiques de vers rétrogradés, d'eschos, de labyrinthes, etc., et de vous estre contenté de les nommer, pour faire voir que vous ne les ignoriés pas et pour avoir lieu de les condanner mesme. (carta del 21 de diciembre de 1659; Tamizey de Larroque 73)

Por otro lado, junto a estas coincidencias, también encontramos algunas ausencias notables en el gramático. Los siguientes autores nombrados por Chapelain no aparecen en la NME: Gil Polo, Góngora, Jáuregui, el Guzmán de Alfarache de Mateo Alemán, La Pícara fustina de Francisco López de Úbeda, el Sarao de Carnestolendas de Gaspar Lucas Hidalgo y Quevedo. Algunas precisiones pueden anotarse:

(i) La continuación (tercera parte) de la Diana de Montemayor, la Diana enamorada de Gaspar Gil Polo (1564) alcanza una importante difusión en Francia, se traduce varias veces y los profesores de español recomiendan su lectura. ${ }^{17}$ Es posible que Lancelot la ignore a propósito porque en 1627 otro maestro, Jerónimo de Texeda, publica una continuación de la Diana supuestamente mejorada, que en realidad no es sino un calco de la versión de Gil Polo. Podría tratarse de una manera de desmarcarse del resto de manualistas de español.

(ii) Con respecto a Góngora, ningún gramático del XVII lo incluye en su nómina de autores, y en esto Lancelot sigue la pauta. Debe de resultar difícil codificar sus construcciones, pues no se trata de un autor precisamente modélico desde el punto de vista de la ansiada regularidad sintáctica del gramático. Ello no significa que figuras como $\mathrm{Pa}-$ tón, Correas o Caramuel, en sus respectivas obras sobre poética, re-

Ciaronescu: "A l'en croire, il a tout lu, ce qui est une rodomontade de pédant. Ce qui'il connaît le mieux, c'est la critique: il a lu López Pinciano et Cascales, ce qui est natural de la part d'un tenant du classicisme orthodoxe; il a lu le Discurso poético de Jáuregui [...] mais, d'une part, il ignore à peu près tout du théatre espagnol et d'autre part [...] il n'apprécie pas Góngora, si ce n'est dans ses compositions burlesques. Ses connaissances et ses critères ne compensent pas l'absence du gout" $(1983,165)$.

17. Según los datos de Cioranescu $(1983,416)$ aparecen tres ediciones bilingües entre 1606 y 1613. 
tórica o elocuencia españolas pasen por alto sus composiciones. Los tres, como Chapelain, tienen palabras -buenas y no tan buenas ${ }^{18}$ sobre la poesía culteranista del cordobés.

(iii) La difusión de la picaresca española en Francia es inmediata y muy efectiva y, dentro de ella, el Guzmán de Alfarache de Mateo Alemán es su muestra más representativa. Ya se ha comentado que Jean Chapelain lo traduce al comienzo de su carrera para utilizarlo en sus clases de español y lo publica en 1619-1620 logrando un enorme éxito editorial. No obstante, mucho ha llovido desde esa época y en 1659 hace ya tiempo que se ha producido ese viraje en su actitud crítica hacia la novela barroca española. Además de renegar de su trabajo de traducción, reprocha el propio estilo de la obra, en su opinión errático y fallido ("Il cloche dans le nombre faute d'art et penche dans l'excès des digressions lasches et foibles"). Puede ser que Lancelot lo obvie a raíz de este comentario negativo, o de nuevo para distanciarse de otros manuales de español o, simplemente, porque no guste de este género.

(iv) Chapelain, en cambio, le recomienda otra obra picaresca como fuente para su poética, la Pícara fustina de Francisco López de Úbeda, e incluso le ofrece un ejemplar si no lo tiene:

L'autheur de la Picara fustina, qui estoit un licenciado de beaucoup d'esprit et de sçavoir, est celuy qui vous pourra le plus éclaicir de ces différences formes poétiques, car il a affecté d'en donner un essay d'une à chacun de ses chapitres de son livre. Si vous ne l'aviés pas, je vous en accommoderay volontiers. (carta del 10 de octubre de 1659; Tamizey de Larroque 57)

La obra se publica por primera vez en 1605 y, aunque de menor difusión que el Guzmán, algunos ejemplares deben de circular en Francia antes de su primera traducción al francés (La narquoise fustine 1636). En ella, cada uno de los capítulos viene acompañado de un suplemento -denominado "aprovechamiento"- donde se subraya la moralidad de la obra y reluce la amplia formación humanística de su autor. Estos son, precisamente, los fragmentos que recomienda Chapelain, ya que en ellos se pueden apreciar las distintas formas poéti-

18. Acerca de las críticas a literatos o muestras literarias en gramáticas españolas, puede consultarse Quijada 2012. 
cas. De nuevo, no parece interesarle a Lancelot y ello puede deberse a su desinterés general por el género picaresco o, tal vez, a su estructura y expresión más sofisticadas, que la hacen de compleja comprensión para el lector extranjero no avanzado.

(v) Con respecto al estilo de Quevedo, la opinión de Chapelain no es del todo favorable, aunque lo salva del grupo de poetas modernos españoles que cultivan un estilo corrompido y forzado ("Quevedo est assez de ces gens là quoyqu'un peu moins que la pluspart des autres”). Lancelot no lo incluye en su canon inicial, pero cuando compendia El arte poética española de Rengifo para la tercera parte inserta un poema completo suyo sobre el descenso de Orfeo a los infiernos. Se trata de una de las primeras apariciones del escritor barroco en una obra lingüística (ya lo había incluido prematuramente Patón en su Elocuencia Española en Arte, de 1604, pero había pasado desapercibido para la gran mayoría de gramáticos, incluido Correas).

\section{Muestras literarias a modo de ejemplos en el cuerpo de la gramática}

Interesa ahora comparar el canon literario del prefacio con el que se desprende de los ejemplos distribuidos en el cuerpo (segundo y tercer capítulos), ${ }^{19}$ puesto que una cuestión es la propuesta teórica y otra, a menudo bien distinta, la utilidad real de los ejemplos literarios:

\begin{tabular}{|l|c|}
\hline \multicolumn{1}{|c|}{ AUTOR/OBRA } & NúMERO DE EJEMPLOS \\
\hline Boscán & 5 \\
\hline Garcilaso de la Vega & 4 \\
\hline Lope de Vega & 3 \\
\hline Cristóbal de Castillejo & 2 \\
\hline Antonio de Guevara (Marco Aurelio) & 1 \\
\hline Alonso de Ercilla & 1 \\
\hline Francisco Quevedo & 1 \\
\hline Juan de Mena & 1 \\
\hline Santa Teresa de Jesús & 1 \\
\hline Jorge Manrique & 1 \\
\hline Total & 20 \\
\hline
\end{tabular}

Tabla 2. Ejemplos literarios en el cuerpo de la NME (con indicación del autor)

19. Se contabilizan solo aquellos casos en que esté indicada la autoría. 
Predominan los poetas líricos, dato comprensible si tenemos en cuenta que la mayor parte de las muestras proceden del tercer capítulo sobre poética. Destacamos, sin embargo, el ejemplo del Libro áureo de Marco Aurelio de Guevara, autor que no aparece en las cartas de Chapelain, pero que es constante en las gramáticas de los Siglos de Oro. A pesar de ello, el ejemplo seleccionado por Lancelot no se rastrea en ninguna otra gramática y obedece a su vocación espiritual: "Ten compassion de los hombres pobres, y tenerla han de ti los Dioses muy ricos" (NME, p. 75)..$^{20}$

A esta nómina de literatos hay que añadir no pocos ejemplos de composiciones anónimas (romances, villancicos, coplas, etc.) extraídos en su mayoría del tratado de poética de Rengifo. ${ }^{21}$ El cotejo entre el último capítulo de la NME y el Arte poética española (1592) certifica la deuda declarada por Lancelot en varias ocasiones: compendia la teoría y los ejemplos del jesuita, trasladando los nombres de los poetas solo cuando este lo hace e ignorando, así, la recomendación de Chapelain de hacerlos siempre explícitos: "Pour authoriser l'ouvrage aussi bien que pour l'essayer, je serois d'avis qu'à chacun vous missiez le nom de l'autheur". Por otro lado, de los doce ejemplos aparecidos en la parte de sintaxis, nueve -es decir, el $75 \%$ - proceden de otro gramático, Antoine Charpentier, que había publicado su Parfaite Methode pour entendre, escrire, et parler la langue espagnole 64 años antes: tres de Boscán, tres de los romances, dos de Garcilaso y uno de Guevara.

\section{Conclusiones}

A lo largo de estas páginas se han ofrecido una serie de claves que han ido despejando el entramado de ejemplos y autoridades literarias de la gramática española de Lancelot. Ante todo, se puede afirmar que la deuda con Rengifo (1592), Charpentier (1596) y Chapelain (cartas de 1659) demuestra el limitado conocimiento sobre la literatura española por parte del gramático de Port Royal y su necesidad de orientación; dicha influencia lleva aparejada, además, la descripción de un estado de lengua anterior al momento de redacción, así como la preferencia por el género lírico.

20. Citamos por la 2. ${ }^{\text {a }}$ edición de 1665 -y no la 1. a de 1660- puesto que esta puede considerarse la versión definitiva revisada por el propio autor que incorpora una serie de mejoras (sobre el análisis ecdótico de la NME, ver Díaz Villalba/Quijada).

21. Mucho se ha escrito sobre la autoría de esta obra. El lector interesado puede consultar una síntesis de las distintas propuestas en Pérez Pascual. 
Siendo esto evidente, no parece justo olvidar las menciones y los ejemplos seleccionados por el propio Lancelot, aparentemente sin intermediarios y derivados de su competencia. Por una parte, se han localizado otros dos ejemplos -sin explicitud de autoría- procedentes de la literatura religiosa: Rivadeneira (Historia eclesiástica del cisma del reino de Inglaterra) y fray Luis de Granada (traducción del Contemptus mundi de Kempis). Por otra, los ejemplos de Castillejo, Montemayor, Lope de Vega y santa Teresa de la tercera parte no se rastrean en el Arte Poética Española de Rengifo. Ello viene a reforzar la idea de que, a pesar de que acuda a recomendaciones de críticos literarios, tratados de poética y gramáticas, Lancelot posee desde luego la formación y erudición suficientes como para seleccionar muestras literarias de primera mano.

Se ha pretendido aquí comprender el proceso de formación del canon de autoridades en las obras gramaticales, en el que las recomendaciones procedentes de la crítica literaria son siempre importantes e incluso, como en este caso, se pueden rastrear documentalmente. Si bien la influencia más directa de Chapelain la detectamos en los paratextos, los ejemplos del interior de la gramática no se alejan del criterio estético del hispanista -aunque como le recuerda, podrían haberse encontrado otros más bellos- y sirven a la perfección para lo que se les requiere, esto es, que sean modelos poéticos y lingüísticos: "Quant aux exemples, il y en a peu de beaux et de rians, mais il n'y en a pas un qui ne puisse servir à l'intention de donner des modelles de ces diverses formes de poësie" (carta de 21 de diciembre de 1659; Tamizey de Larroque 72 ).

\section{OBRAS CITADAS}

\section{Fuentes}

Charpentier, Antoine. La Partaicte Methode pour entendre, escrire, et parler la langue espagnole. Paris: Lucas Breyer, 1596.

Díaz Rengifo, Juan. Arte poética española. Madrid: Juan de la Cuesta, 1592.

Lancelot, Claude. Nouvelle Methode pour apprendre facilement et en peu de temps la langue espagnole: Seconde edition, reveuë \& corrigée de nouиeau. Paris: Pierre le Petit, 1665.

Tamizey de Larroque, Philippe, ed. Lettres de Jean Chapelain, de l'Académie Française. Collection de documents inédits sur l'histoire de France. Vol. 2 (2 enero de 1659-20 diciembre de 1672). Paris: Imprimèrie Nationale, $1883.55-58$ y $72-75$. 


\section{Estudios}

Briquet, Apollin. "La bibliothèque de Jean Chapelain, l'auteur du poème de La Pucelle". Bulletin du Bibliophile et du Bibliothècaire (1872): 332-48.

Cioranescu, Alejandro. Bibliografía franco-española (1600-1715). Anejos del Boletín de la Real Academia Española 36. Madrid: RAE, 1977.

Cioranescu, Alejandro. Le Masque et le visage: Du baroque espagnol au classicisme français. Ginebra: Droz, 1983.

Collas, George. Un Poète protecteur des lettres au XVIIe siècle, Jean Chapelain (1595-1674): Étude historique et littéraire d'après des documents inédites. Paris: Perrin, 1912.

Collet Sedola, Sabina. "La connaissance de l'espagnol en France et les premières grammaires hispano-françaises (1550-1700)". Tesis de tercer ciclo inédita. Université Paris III, 1973-1974.

Collet Sedola, Sabina. "Les hispanisants français du XVIIe siècle et la langue italienne". Italia ed Europa nella linguistica del Rinascimento. Ed. Mirko Tavoni. Ferrara: Istituto di studi Rinascimentali Ferrara, 1991. 443-58.

Collet Sedola, Sabina. "Gramáticos y gramáticas: España en Francia (16001650)". Studia Aurea (Actas del III Congreso de la AISO). Eds. Ignacio Arellano y otros. Vol. 1. Pamplona: Griso, 1996. 161-68.

Colomer, José Luis. "España o la barbarie: Jean Chapelain, traductor y crítico de la literatura española”. Traducción y adaptación cultural: España-Francia. Coords. Francisco Lafarga y M. ${ }^{a}$ Luisa Donaire. Oviedo: Servicio de Publicaciones de la Universidad de Oviedo, 1991. 603-12.

Díaz Villalba, Alejandro y Carmen Quijada Van den Berghe. "Propuesta crítica para una nueva edición de la Nouvelle methode pour apprendre facilement et en peu de temps la langue espagnole de Claude Lancelot (1660)". Sintagma: revista de Lingiuística 28 (2016): 43-58.

Esparza Torres, Miguel Ángel. Bibliografía temática de bistoriografía linguiística española: fuentes secundarias. Hamburgo: Helmut Buske, 2008.

Esteba Ramos, Diana. "Los ejemplos en las gramáticas del español como lengua extranjera: siglo de oro". Tesis doctoral. Málaga: Universidad de Málaga, 2005.

Esteba Ramos, Diana. "Las gramáticas del español frente a las gramáticas del italiano de los maestros de lenguas del s. XVII: escenarios de continuidad". Métodos y resultados actuales en Historiografía de la Lingüística. Eds. M. ${ }^{a}$ Luisa Calero y otros. Münster: Nodus Publikationen, 2014. 173-82.

Fournier, Jean-Marie y Valérie Raby. "Grammaire générale et grammaires particulières: relire la Grammaire de Port-Royal à la lumière des Métho- 
des italienne et espagnole". Documents pour l'histoire du français langue étrangère ou seconde 51 (2013): 59-85.

Gómez Asencio, José J. "Cervantes, buen hablista mal hablado: el juicio de los gramáticos (entre 1625 y 1872)”. El español a través del tiempo: estudios ofrecidos a Rafael Cano Aguilar. Coord. Araceli López Serena y otros. Vol. 2. Sevilla: Universidad de Sevilla, 2016a. 1081-1105.

Gómez Asencio, José J. "Del valor de las autoridades y de sus muestras de lengua (en la gramática tradicional española)". La torre di Babele: rivista di letteratura e lingüistica 12 (2016b).

Hernández Sánchez, Eulalia y María Isabel López Martínez. "El «uso» en el Nouvelle Méthode pour apprendre... la langue espagnole de De Trigny". Actas del I Congreso Internacional de Historia de la Lengua Española. Ed. Manuel Ariza. Madrid: Arco/Libros, 1988. 1225-31.

Hernández Sánchez, Eulalia y M. ${ }^{a}$ Isabel López Martínez. "Introducción”. Claude Lancelot. Nouvelle Methode pour apprendre facilement et en peu de temps la langue espagnole. Eds. Eulalia Hernández Sánchez y M. ${ }^{a}$ Isabel López Martínez. Murcia: Servicio de Publicaciones de la Universidad de Murcia, 1990. 9-90.

Jouhaud, Christian. "Sur le statut d'homme de lettres au XVIIe siècle: La correspondance de Jean Chapelain (1595-1674)". Annales: Histoire, Sciences Sociales 49.2 (1994): 311-47.

Lanson, Gustave. "Études sur les rapports de la littérature française et de la littérature espagnole au XVIIème siècle (1600-1660)". Revue d'Histoire Littéraire de la France 3 (1896): 45-70 y 321-31.

Lliteras, Margarita. "Sobre la formación del corpus de autoridades en la gramática española”. Historiographia Linguistica 24.1/2 (1997): 57-72.

López Alonso, Covadonga. "El ejemplo literario como autoridad en la Gramática de la lengua castellana de 1771". Homenaje a Elena Catena. Eds. Antonio Lara y otros. Madrid: Castalia, 2001. 303-20.

Losada Goya, José Manuel. Bibliographie critique de la littérature espagnole en France au XVIIe: présence et influence. Ginebra: Droz, 1999.

Martínez Gavilán, María Dolores. "Las ideas lingüísticas en España en el siglo XVII: los tratados gramaticales". Tesis doctoral. León: Universidad de León, 1989.

Maux-Piovano, Marie-Hélène. Les débuts de la didactique de l'espagnol en France: les premières grammaires pratiques (1596-1660). Lille: Atelier National de Reproduction des Thèses, 2000. 
Maux-Piovano, Marie-Hélène. "Las gramáticas castellanas para extranjeros: el foco francés". El castellano y su codificación gramatical, II: De 1614 (B. Fiménez Patón) a 1697 (F. Sobrino). Dir. José J. Gómez Asencio. Burgos: Instituto Castellano y Leonés de la Lengua, 2008. 387-410.

Medina Morales, Francisca. "La Nouvelle Méthode de Lancelot: estudio de sus anotaciones diastráticas". Nuevas aportaciones a la bistoriografía linguiística. Ed. Cristóbal José Corrales Zumbado y otros. Vol II. Madrid: Arco/Libros, 2005. 1125-34.

Morel-Fatio, Alfred. Études sur l'Espagne. Paris: F. Vieweg, 1888.

Morel-Fatio, Alfred. Ambrosio de Salazar et l'étude de l'espagnol en France sous Louis XIII. Paris-Toulouse: Picard \& Privat, 1901.

Péligry, Christian. "La pénétration du livre espagnol à Paris dans la première moitié du XVIIe siècle (1598-1661)". Thèses de l'École de Chartres (1974): 191-95.

Péligry, Christian. "L'accueil réservé au livre espagnol par les traducteurs parisiens dans la prémière moitié du XVIIe siècle (1598-1661)". Mélanges de la Casa de Velázquez 11 (1975): 163-76.

Péligry, Christian. "Un hispanista francés del siglo XVII: Jean Chapelain (1595-1674)”. El libro antiguo español. Eds. M. ${ }^{a}$ Luisa López Vidriero y Pedro M. Cátedra. Vol. 1. Salamanca: Sociedad Española de Historia del Libro/Universidad de Salamanca/Biblioteca Nacional de Madrid, 1988a. 305-16.

Péligry, Christian. "Le rayonnement culturel de l'Espagne". Catalogue des livres espagnols des ХИІе et ХVIIe siècles conservés à la Bibliothèque Municipale de Troyes. Eds. Antonio Iglesias-Diestre y Jean-Paul Oddos. Bordeaux: Société des Bibliophiles de Guyenne, 1988b. 7-47.

Pérez Pascual, Ángel. "El verdadero autor del Arte poética española (Salamanca, 1592) de Juan Díaz Rengifo y el uso de seudónimos en los escritores jesuitas del Siglo de Oro". Actas del IV Congreso Internacional de la AISO. Eds. M. ${ }^{a}$ Cruz García de Enterría y Alicia Cordón Mesa. Vol. 2. Alcalá de Henares: Servicio de publicaciones de la Universidad de Alcalá de Henares, 1998. 1223-36.

Quijada Van den Berghe, Carmen. "Pautas para el estudio de las autoridades y el canon en las gramáticas del español del siglo XVII". El castellano y su codificación gramatical, II: De 1614 (B. Fiménez Patón) a 1697 (F. Sobrino). Dir. José J. Gómez Asencio. Burgos: Fundación Instituto Castellano y Leonés de la Lengua, 2008. 641-66. 
Quijada Van den Berghe, Carmen. “Autoridades y canon en gramáticas del español del siglo XVIII". El castellano y su codificación gramatical, III: De 1700 a 1835. Dir. José J. Gómez Asencio. Burgos: Fundación Instituto Castellano Leonés de la Lengua Española, 2011. 805-31.

Quijada Van den Berghe, Carmen. "Autores malditos: el anti-canon literario en la historia de la gramática española". Historiografía linguiística: líneas actuales de investigación. Eds. Elena Battaner Moro, Vicente Calvo Fernández y Palma Peña Jiménez. Vol. 2. Münster: Nodus Publikationen, 2012. 711-25.

Sáez Rivera, Daniel. "La lengua de las gramáticas y métodos de español como lengua extranjera en Europa (1640-1726)". Tesis doctoral. Madrid: Universidad Complutense de Madrid, 2007.

Sainte-Beuve, Charles Augustin. Port-Royal. 1840-1859. 3 vols. Paris: Gallimard, 1953-1955. 